\title{
A CLINICAL STUDY OF EFFECTIVENESS OF MANNHEIM PERITONITIS INDEX IN PREDICTING MORBIDITY AND MORTALITY OF PATIENTS WITH HOLLOW VISCUS PERFORATION: IN A TERTIARY CARE HOSPITAL
}

\author{
Bhanuprakash K. $R^{1}$, Nagaraj Shankreppa², Prashanth Kumar B3
}

${ }_{1}^{1}$ Assistant Professor, Department of General Surgery, Bangalore Medical College and Research Institute, Bangalore.

2Post Graduate, Department of General Surgery, Bangalore Medical College and Research Institute, Bangalore.

${ }^{3}$ Post Graduate, Department of General Surgery, Bangalore Medical College and Research Institute, Bangalore.

\section{ABSTRACT}

\section{BACKGROUND AND OBJECTIVES}

Peritonitis due to hollow viscous perforation is one of the most common surgical emergencies in surgical practice. This may be due to persistence of the various risk factors among population like H. pylori infection, NSAID's, enteric fever and several others. This condition needs an emergency surgical intervention, a scoring system should be able to assess the need, type and quality of the care required for a particular patient. Realizing the need for a simple accurate scoring system in these conditions, the present study was undertaken to evaluate the performance of MPI scoring system in predicting the risks of morbidity and mortality in patients with peritonitis due to hollow viscous perforation.

\section{METHODOLOGY}

Fifty consecutive patients clinically diagnosed as having peritonitis due to hollow viscous perforations was taken for the study over a period of 18 months from July 2014 to December 2015. Pre-operative patients were investigated for air under the diaphragm using upright chest X-ray and erect abdomen X-rays. Routine blood investigations and WIDAL tests were done. Patient resuscitated. Patients with general peritonitis due to trauma were excluded from the study.

\section{RESULTS}

Out of 50 patients there were 40 (80\%) males and 10 (20\%) females, thus the male:female ratio was 4:1. Their ages ranged from 16-58 years. There were 32 patients presented early and 18 patients presented lately. The patients presented to the hospital with spectrum of symptoms. All the patients had pain abdomen to present with 33 had dehydration and 16 had shock on presentation. In these 50 patients, 48 patients had single perforations and 2 had multiple perforations. The single perforation was treated with simple Graham's patch and resection anastomosis was done in cases of multiple perforations. The patients were observed for complications of surgery. The mean hospital stay was 13.28 days. We lost 6 cases. There were 9 cases of wound infection, 2 cases of wound dehiscence, 4 cases of respiratory tract infections. The blood culture was positive in 4 cases and the culture yielded Salmonella typhi.

\section{CONCLUSION}

Perforation is one of the most common surgical emergency encountered by the general surgeon. The number of perforations and the peritoneal contamination and the delay in getting medical facility-surgery, shock at the time of presentation at hospital are directly proportional to the morbidity and mortality. Availing early medical facility, which is a modifiable risk factor. If timely early medical attention is sought, majority of morbidity and mortality can be tackled.

\section{KEYWORDS}

Hollow Viscous, Gastric, Duodenal and Ileal Perforation, Prognosis.

HOW TO CITE THIS ARTICLE: Bhanuprakash KR, Shankreppa N, Prashanth Kumar B. A clinical study of effectiveness of Mannheim peritonitis index in predicting morbidity and mortality of patients with hollow viscus perforation: in a tertiary care hospital. J. Evolution Med. Dent. Sci. 2016;5(38):2329-2334, DOI: 10.14260/jemds/2016/541

\section{INTRODUCTION \\ Peritonitis due to hollow viscous perforation continues to be one of the most common surgical emergency. This condition most of the times needs an emergency surgical intervention, a scoring system should be able to assess the need, type and quality of the care required for a particular patient. The Mannheim peritonitis index provides an early and reliable}

Financial or Other, Competing Interest: None.

Submission 27-03-2016, Peer Review 23-04-2016,

Acceptance 28-04-2016, Published 12-05-2016.

Corresponding Author:

Dr. Nagaraj Shankreppa,

Room No. 217, BMC Men's PG Hostel,

Near Amanath Co-Op. Bank,

Shivajinagar, Bangalore.

E-mail: nagarajdoc76@gmail.com

DOI: $10.14260 /$ jemds $/ 2016 / 541$ means of risk evaluation and classification of pts. with peritoneal inflammation. ${ }^{1}$

Wacha and co-workers (1987) developed a separate peritonitis index, Mannheim Peritonitis Index (MPI) which incorporated information regarding age, gender, organ failure, cancer, duration of perforation, involvement of colon, extent of spread within the peritoneum and the characteristic of peritoneal fluid to define risk scores ranges from 00 to 47.1

A Billing et al, divided pts. into three categories of severity of MPI $<21,21-29$ and $>29$. MPI not only reliable in predicting mortality, but also be used for comparative study. Patients with scores of $<21$ has a mortality rate of $0-2.3 \%$ and those with MPI between 21-29 had a mortality rate of approximately $65 \%$ and MPI score $>29$ had highest mortality up to $>80 \% .^{2}$

Pacelli concluded that MPI and APACHE correctly predicted death as outcome, but MPI was easier to calculate. ${ }^{3}$ 
Notanh AY, Salini J, Rahimani H, Fesharaki MH, Abbasi A have shown important cut-off point to be 21 and 29 when using MPI with mortality of $60 \%$ and up to $100 \%$ for scores more than 29.4

In 1980. Fry et al showed that mortality after major operative procedures increased as the number of failed organs increases. ${ }^{5}$ Mortality was $3 \%$ with no organ failure, which increased to $30 \%$ with one organ failure and to $100 \%$ with 4 major organ failure.

Lohisiriwat et al concluded that average MPI score in patients with 30 days mortality was 25.92 . The average score among the patients with complications was 25.93, when compared to those without complications average score was 19.51. They concluded that MPI scoring system was more helpful in predicting the morbidity in patients. ${ }^{6}$

Kusumoto et al used MPI score of 26 as cut-off value to predict the mortality. The sensitivity of the cut-off value for mortality was 77.7 and specificity was 97.7 . The mortality for the group $<26$ was $3.8 \%$ and for the group with score $>26$ it was $41 \% .^{7}$

Abrar Maqbool Quereshi et al concluded that the mortality among the patients with MPI score $<20$ was $1.9 \%$. Mortality increased to $21.9 \%$ for score $>30 .{ }^{8}$ The significance was higher for the factors $>59$ years of age, malignancy, preoperative duration of $>24$ hours and cloudy intraperitoneal exudates among the different variables used in this scoring system. Ohmann et al reported duodenal ulcer perforation as the commonest cause for peritonitis in his series. ${ }^{9}$

Realizing the need for a simple accurate scoring system in these conditions, the present study was undertaken to evaluate the performance of MPI scoring system in predicting the risk of morbidity and mortality in patients with peritonitis due to hollow viscous perforation. Several scoring systems are in place to stratify the patients with peritonitis due to hollow viscous perforation like APS, SIS, APACHE and BOEYS. Utilization of scoring systems would be of great help in salvaging a priceless life of a patient. Our study is aimed at testing the effectiveness of Mannheim Peritonitis Index.

\section{AIMS AND OBJECTIVES OF THE STUDY}

Aim is to predict the risk of mortality and morbidity in patients with peritonitis due to hollow viscous perforation. Assessment of surgical risk in these patients is to help in choosing the modality of post-op management in a particular patient.

This study attempts to evaluate the prognostic value of MPI scoring system in patients with peritonitis due to hollow viscous perforation to assess it as a clinical tool in stratifying these patients according to individual surgical risk.

\section{MATERIALS AND METHODOLOGY}

\section{Source of Data}

Total of 50 patients with peritonitis due to hollow viscous perforation who presented to Bangalore Medical College and Research Institute, Bangalore, from July 2014 to December 2015.

\section{METHODS}

Inclusion Criteria: All patients above 16 years undergoing surgery for peritonitis due to hollow viscous perforation due to Acid peptic disease, Typhoid, Tuberculosis, Gangrenous cholecystitis, Appendicitis, Malignancy and given written consent to participate in this study.
Exclusion Criteria: Patients with hollow viscous perforation due to trauma, patients with any other significant illness, which is likely to affect the outcome more than the disease in study and pregnant mothers and patients not willing to give consent for study.

\section{METHODOLOGY}

Fifty consecutive patients clinically diagnosed as having peritonitis due to hollow viscous perforation was taken for the study over a period of 18 months from July 2014 to December 2015. Pre-operative patients were investigated for the air under the diaphragm using upright chest X-ray and erect abdomen X-rays. Routine blood investigations, packed cell volume, serum electrolytes, urea and creatinine levels, ECGs were also taken. Diagnosis was further supported by intraoperative findings of gastric, duodenal or ileal perforation with associated peritoneal soilage. Pre-operative resuscitation was done including correcting anaemia, correcting electrolyte imbalances, adequate urine output was obtained and patients were brought out of shock. Patients were kept nil by mouth. Inj. tetanus toxoid $0.5 \mathrm{cc}$ was given intramuscularly. One gram of Inj. Ceftriaxone given as prophylactic antibiotic. On all patient's general anaesthesia was used. Exploratory laparotomy was done with midline incision. Operative findings were noted including the amount of fluid, pus and fecal matter and peritoneal contamination. The gastric and duodenal perforations were closed with Graham's omental patch and the edges of the ileal perforations were freshened and primary closure was done transversely in two layers. Resection anastomosis done in selected cases. Edge biopsy from the ulcer sent for histopathological examination. Peritoneal cavity was irrigated with copious amount of normal saline. Drains were inserted to drain the paracolic gutter and pelvic cavity; these were connected to graduated plastic bags. Wound was closed with mass closure technique and the appropriate antibiotics were put. The majority of cases were treated with IV Ceftriaxone and Metronidazole for a period of ten days. Attention was given to wound infection, wound dehiscence, residual intra-abdominal abscess, faecal fistula and death.

Once diagnosis of peritonitis had been determined by operative findings, the patient was enrolled into the study. Using history, clinical examination and lab values risk factors found in MPI were classified according to values indicated and individual variable scores were added to establish MPI score. The cases were first grouped into three as described by Billing: those below 21 pts., between 21-29 pts. and those above 29 pts. 2.

In addition to personal data such as name, age, sex, etc., the following information was registered: file number; dates of admission and discharge from the hospital; days hospitalized; date of surgery and information related to illness (Surgical findings, medical treatment and evolution of illness). Patient evolution was followed, occurrence of complications and discharge due to improvement or death. Time elapsed from initial diagnosis to moment of event (Death or discharge from hospital) was determined.

Outpatient follow-up was continued for 30 days to establish perioperative morbidity and mortality. The minimum possible score was zero, if no adverse factor were present and maximum was 47 if presence of all were confirmed. Analysis was done with each variable in the scoring 
system as an independent predictor of morbidity or mortality and the scoring system as a whole.

\section{STATISTICAL ANALYSIS}

The data was analysed using SPSS software version 16.3. Each variable in the MPI score along with other patient variables was analysed using Chi square analysis with various outcomes that were noted in the study. $P$ value $<0.05$ was taken as significant in this study. The results were averaged (mean+standard deviation) for each parameter for continuous data and numbers and percentage for categorical data presented in table and figure. Proportions were compared using Chi-square test of significance.

\section{RESULTS}

The number of post-operative complications, duration of ICU and hospital stay proportionately increased with the MPI score. Out of the 8 variables used in this scoring system, duration of pain, intraperitoneal fluid and organ failure on admission carried more significance in predicting the morbidity in the postop period than the other variables. Males accounted for $80 \%$ of the patients in the present study, whereas most of the other studies show equal sex distribution. ${ }^{10,11} 70 \%$ of the patients were less than 50 years of age, which is similar to earlier studies.

About $60 \%$ of the study group presented with pain abdomen of less than 24 hours' duration. It was seen in this study that longer the duration of pain, higher was the morbidity in the post-op period.

\begin{tabular}{|c|c|c|}
\hline Duration of Pain & Frequency & Percentage \\
\hline$<24$ hours & 32 & 64 \\
\hline 1 to 5 days & 16 & 32 \\
\hline$>5$ days & 02 & 4 \\
\hline Total & $\mathbf{5 0}$ & $\mathbf{1 0 0}$ \\
\hline
\end{tabular}

The most common site of perforation was duodenum (58\%), ileal perforation being the next common. ${ }^{9}$

\begin{tabular}{|c|c|c|}
\hline Origin & Frequency & Percentage \\
\hline Gastric & 05 & 10 \\
\hline Duodenal & 29 & 58 \\
\hline Ileal & 09 & 18 \\
\hline Appendicular & 07 & 14 \\
\hline Total & $\mathbf{5 0}$ & $\mathbf{1 0 0}$ \\
\hline
\end{tabular}

Majority (50\%) had clear fluid exudate.

\begin{tabular}{|c|c|c|}
\hline Type of Exudate & Frequency & Percentage \\
\hline Clear & 25 & 50 \\
\hline Purulent & 13 & 26 \\
\hline Feculent & 12 & 24 \\
\hline Total & $\mathbf{5 0}$ & $\mathbf{1 0 0}$ \\
\hline
\end{tabular}

$58 \%$ of the study population had no post-operative complications, $20 \%$ had 2 or more complications.

$64 \%$ of the study population was in the low risk group (Scores $<22$ ) and $14 \%$ were in high risk (scores $>29$ ). Patients with organ failure on admission, longer duration of illness before the surgery, diffuse peritonitis and feculent exudates were more likely to have higher scores and hence fall into high risk group than their counterparts.

\begin{tabular}{|c|c|c|}
\hline MPI Scores & Frequency & Percentage \\
\hline$<22$ & 32 & 64 \\
\hline $22-29$ & 11 & 22 \\
\hline$>29$ & 07 & 14 \\
\hline Total & $\mathbf{5 0}$ & $\mathbf{1 0 0}$ \\
\hline
\end{tabular}

$90 \%$ of the population which had no post procedure complications had a score of $<22(p<0.002)$, whereas $70 \%$ of the patients with MPI of $>29$ had 2 or more complications during the postop period. The pulmonary complications in the form of postop pneumonia, pleural effusion which required continuous monitoring of oxygen saturation, nebulization and hence lead to longer post-op recovery; $>80 \%$ of patients with $>29$ had some form of pulmonary complications, which was only about $10 \%$ in patients with scores $<22$. $(\mathrm{P}<0.005)$ were significantly higher as the score increased.

\begin{tabular}{|c|c|c|c|c|}
\hline $\begin{array}{c}\text { Pulmonary } \\
\text { Complications }\end{array}$ & $\begin{array}{c}\text { Score } \\
\mathbf{2 2 2}\end{array}$ & $\begin{array}{c}\text { Score } \\
\mathbf{2 2 - 2 9}\end{array}$ & $\begin{array}{c}\text { Score } \\
\mathbf{2} \mathbf{2 9}\end{array}$ & Total \\
\hline No & 29 & 7 & 1 & 37 \\
\hline & $78.4 \%$ & $18.9 \%$ & $2.7 \%$ & $100 \%$ \\
\hline Yes & 3 & 4 & 6 & 13 \\
\hline & $23.1 \%$ & $30.8 \%$ & $46.2 \%$ & $100 \%$ \\
\hline Total & $\mathbf{3 2}$ & $\mathbf{1 1}$ & $\mathbf{7}$ & $\mathbf{5 0}$ \\
\hline & $64 \%$ & $22 \%$ & $14 \%$ & $100 \%$ \\
\hline
\end{tabular}

The development of ARDS in these patients was well predicted with this scoring system; $50 \%$ of the patients who developed ARDS in their post-operative course had a score of more than $29 ; 30 \%$ of the patients with score $>29$ eventually developed ARDS in the post-operative course.

\begin{tabular}{|c|c|c|c|c|}
\hline ARDS & $\begin{array}{c}\text { Score } \\
<\mathbf{2 2}\end{array}$ & $\begin{array}{c}\text { Score } \\
\mathbf{2 2 - 2 9}\end{array}$ & $\begin{array}{c}\text { Score } \\
\mathbf{2 2 9}\end{array}$ & Total \\
\hline No & 32 & 9 & 5 & 46 \\
\hline & $69.6 \%$ & $19.6 \%$ & $10.9 \%$ & $100 \%$ \\
\hline Yes & 0 & 2 & 2 & 4 \\
\hline & $0 \%$ & $50 \%$ & $50 \%$ & $100 \%$ \\
\hline Total & $\mathbf{3 2}$ & $\mathbf{1 1}$ & $\mathbf{7}$ & $\mathbf{5 0}$ \\
\hline & $64 \%$ & $22 \%$ & $14 \%$ & $100 \%$ \\
\hline
\end{tabular}

The post-op complications were significantly higher in the group with score $>29$. This included the surgical site infections, pulmonary, renal complications and development of multi-organ failure.

\begin{tabular}{|c|c|c|c|c|}
\hline SSI & Score $<22$ & Score 22-29 & Score $>29$ & Total \\
\hline No & 28 & 06 & 03 & 37 \\
\hline & $75.7 \%$ & $16.2 \%$ & $8.1 \%$ & $100 \%$ \\
\hline Yes & 4 & 5 & 4 & 13 \\
\hline & $30.8 \%$ & $38.5 \%$ & $30.8 \%$ & $100 \%$ \\
\hline Total & $\mathbf{3 2}$ & $\mathbf{1 1}$ & $\mathbf{0 7}$ & $\mathbf{5 0}$ \\
\hline & $64 \%$ & $22 \%$ & $14 \%$ & $10 \%$ \\
\hline
\end{tabular}

The primary cause of prolonged hospital stay after the operation in patients with secondary bacterial peritonitis is pulmonary complications and MODS and this is despite the technical success of the initial operation. Peritonitis may 
induce a systemic inflammatory response, in which the lungs succumb more often and earlier than other remote organs. ${ }^{12}$

ICU stay and ward stay is significantly prolonged in patients with higher scores. There is a proportionate increase in the duration of stay with increase in scores; $90 \%$ of the patients who were discharged within 10 days had a score of $<22$.

\begin{tabular}{|c|c|c|c|c|}
\hline ICU STAY & $\begin{array}{c}\text { Score } \\
<\mathbf{2 2}\end{array}$ & $\begin{array}{c}\text { Score } \\
\mathbf{2 2 - 2 9}\end{array}$ & $\begin{array}{c}\text { Score } \\
\mathbf{2 2 9}\end{array}$ & Total \\
\hline < than 5 days & 32 & 07 & 04 & 43 \\
\hline & $74.4 \%$ & $16.3 \%$ & $9.3 \%$ & $100 \%$ \\
\hline $6-10$ days & 00 & 04 & 01 & 05 \\
\hline & $00 \%$ & $80 \%$ & $20 \%$ & $100 \%$ \\
\hline$>$ than 10 days & 00 & 00 & 02 & 02 \\
\hline & $00 \%$ & $00 \%$ & $100 \%$ & $100 \%$ \\
\hline
\end{tabular}

$57 \%$ of the patients who required inotropic support in the post-op period had a score of $>29$ and only 1 patient (14\%) required inotropes with a score $<22 ; 50 \%$ of the patients who required mechanical ventilation had score of $>29$. Score of $>29$ indicate a higher risk of need for inotropes and mechanical ventilation.

Pts. requiring inotropes in post-op period

\begin{tabular}{|c|c|c|c|c|}
\hline Inotropes & $\begin{array}{c}\text { Score } \\
<\mathbf{2 2}\end{array}$ & $\begin{array}{c}\text { Score } \\
\mathbf{2 2 - 2 9}\end{array}$ & $\begin{array}{c}\text { Score } \\
\mathbf{> 2 9}\end{array}$ & Total \\
\hline No & 31 & 09 & 03 & 43 \\
\hline & $72.1 \%$ & $20.9 \%$ & $07 \%$ & $100 \%$ \\
\hline Yes & 01 & 02 & 04 & 07 \\
\hline & $14.3 \%$ & $28.6 \%$ & $57.1 \%$ & $100 \%$ \\
\hline Total & $\mathbf{3 2}$ & $\mathbf{1 1}$ & $\mathbf{0 7}$ & $\mathbf{5 0}$ \\
\hline & $\mathbf{6 4 \%}$ & $\mathbf{2 2 \%}$ & $\mathbf{1 4 \%}$ & $\mathbf{1 0 0 \%}$ \\
\hline
\end{tabular}

Pts. requiring mechanical ventilation

\begin{tabular}{|c|c|c|c|c|}
\hline $\begin{array}{c}\text { Mech } \\
\text { Ventilation }\end{array}$ & Score $<22$ & $\begin{array}{c}\text { Score } \\
\mathbf{2 2 - 2 9}\end{array}$ & $\begin{array}{c}\text { Score } \\
\mathbf{> 2 9}\end{array}$ & Total \\
\hline No & 31 & 09 & 04 & 44 \\
\hline & $70.5 \%$ & $20.5 \%$ & $9.0 \%$ & $100 \%$ \\
\hline Yes & 01 & 02 & 03 & 06 \\
\hline & $16.7 \%$ & $33.3 \%$ & $50 \%$ & $100 \%$ \\
\hline Total & $\mathbf{3 2}$ & $\mathbf{1 1}$ & $\mathbf{0 7}$ & $\mathbf{5 0}$ \\
\hline & $\mathbf{6 4 \%}$ & $\mathbf{2 2 \%}$ & $\mathbf{1 4 \%}$ & $\mathbf{1 0 0 \%}$ \\
\hline
\end{tabular}

\section{OTHER INDIVIDUAL PARAMETERS}

\section{Site of Perforation}

Duodenal perforations $>80 \%$ cases had an uneventful recovery as indicated by lesser post-op complications, comparatively less requirement of inotropes and mechanical ventilation and lesser hospital stay. Ileal and appendicular perforations had higher rates of post-op complications and need for intensive care.

\begin{tabular}{|c|c|c|c|c|c|}
\hline $\begin{array}{c}\text { No. of } \\
\text { Complications }\end{array}$ & Gastric & Duodenal & Ileal & Appendicular & Total \\
\hline 0 & 01 & 24 & 02 & 02 & 29 \\
\hline 1 & 02 & 03 & 02 & 03 & 10 \\
\hline
\end{tabular}

\begin{tabular}{|c|c|c|c|c|c|}
\hline 2 & 00 & 01 & 03 & 02 & 06 \\
\hline 3 & 01 & 01 & 00 & 00 & 02 \\
\hline 4 & 01 & 00 & 02 & 00 & 03 \\
\hline Total & $\mathbf{0 5}$ & $\mathbf{2 9}$ & $\mathbf{0 9}$ & $\mathbf{0 7}$ & $\mathbf{5 0}$ \\
\hline & $10 \%$ & $58 \%$ & $18 \%$ & $14 \%$ & $100 \%$ \\
\hline
\end{tabular}

\section{Type of Exudate}

Presence of feculent or purulent exudates was reflected in higher eventual scores. Feculent and purulent exudates were associated with significantly increased post-op complications requiring increased hospital stay. Up to $80 \%$ of the patients with clear exudates had no post-op complications, which dropped to only $30 \%(p<0.005)$ with the other type. However, there was no statistically significant difference between feculent and purulent exudates, both having similar complication profiles.

\begin{tabular}{|c|c|c|c|c|}
\hline Score & Clear & Purulent & Feculent & Total \\
\hline $\begin{array}{c}\text { Score } \\
<22\end{array}$ & 24 & 05 & 03 & 32 \\
\hline & $75 \%$ & $15.6 \%$ & $9.4 \%$ & $100 \%$ \\
\hline $\begin{array}{c}\text { Score } \\
22-29\end{array}$ & 01 & 06 & 04 & 11 \\
\hline & $9.1 \%$ & $54.5 \%$ & $36.5 \%$ & $100 \%$ \\
\hline $\begin{array}{c}\text { Score } \\
>29\end{array}$ & 00 & 02 & 05 & 07 \\
\hline & $00 \%$ & $28.6 \%$ & $71.4 \%$ & $100 \%$ \\
\hline Total & $\mathbf{2 5 ( 5 0 \% )}$ & $\mathbf{1 3 ( 2 6 \% )}$ & $\mathbf{1 2 ( 2 4 \% )}$ & $\mathbf{5 0}(\mathbf{1 0 0} \%)$ \\
\hline
\end{tabular}

\section{Duration of Pain}

The study population which presented within $24 \mathrm{hrs}$. of the pain onset had significantly $(\mathrm{p}<0.05)$ better outcome compared with their counterparts. This was reflected in lesser post-op complications, shorter ICU and hospital stay. None of the patients in this group required post-op inotropes or mechanical ventilator. As the duration of pain increased morbidity associated also proportionately increased.

\begin{tabular}{|c|c|c|c|c|}
\hline $\begin{array}{c}\text { No. of } \\
\text { Complications }\end{array}$ & $\begin{array}{c}\text { Duration of } \\
\text { Pain <than 1 } \\
\text { day }\end{array}$ & $\begin{array}{c}\text { Pain } \\
\mathbf{1 - 5} \text { days }\end{array}$ & $\begin{array}{c}>\text { Than } \\
\mathbf{5} \text { days }\end{array}$ & Total \\
\hline 0 & 20 & 09 & 00 & 29 \\
\hline 1 & 00 & 08 & 02 & 10 \\
\hline 2 & 00 & 04 & 02 & 06 \\
\hline 3 & 00 & 02 & 00 & 02 \\
\hline 4 & 00 & 01 & 02 & 03 \\
\hline Total & $\mathbf{2 0}$ & $\mathbf{2 4}$ & $\mathbf{0 6}$ & $\mathbf{5 0}$ \\
\hline
\end{tabular}

\section{Organ Failure on Admission}

Patient presenting with any organ failure due to hollow viscous perforation was significantly associated with $(\mathrm{p}<0.005)$ increased morbidity; $65 \%$ of the patients with no organ failure on admission had uneventful recovery, $97 \%$ of the same population had $<2$ post-op complications. On the other hand, $66 \%$ of the patients with organ failure on admission had $>2$ complications in the post-op; $>90 \%$ of the patients with organ failure needed post-op inotropes and mechanical ventilation, whereas it was the same percentage of patients who did not require inotropes in the other group; $>50 \%$ of the patients with organ failure had pulmonary complications which was $<3 \%$ in the other group. 


\section{DISCUSSION}

There is no ideal scoring system for the pre-operative assessment of patients needing emergency surgery. Some preoperative scoring systems provide approximate estimates of mortality risk, but none have been shown to be sufficiently specific for use on individual patients. At present the Fitness Score has greatest specificity ( $80 \%)$, but would not be easy to use on all emergency admissions due to significantly large number (26) of variables to be collected and few variables like diagnosis of malignancy may not be available in the preop settings. Post-operative scoring systems such as P-POSSUM probably provide more accurate predictions, but are not useful in pre-operative assessment. Unfortunately, there are very few studies that have revisited old scoring systems or attempted to compare systems to assess which is best. Most articles in this field have proposed another new system. The timing of data collection to create risk scores is seldom mentioned in the literature. Not only do physiological values vary during the acute admission making the scores obtained by them unreliable, but there is evidence that to include operative findings and post-operative parameters on ICU improves the accuracy of the prediction. Although a score at initial assessment would help triage and plan treatment, comparative audit with post-operative scores remains the most useful function of scoring systems at present.

Even if accurate pre-operative predictions of outcome were possible by estimation of a risk score, an expert surgical opinion would be required to interpret these predictions at the bedside. An experienced clinician can not only assess prognosis, but also weigh up the local facilities available, the patient's quality of life and ethical issues as well as considering the patient or relative's wishes. Scoring will never replace clinical judgment. Scoring systems are generated and validated on specific populations that may be substantially different from the patients being scored in a different hospital. One potential resolution would be for each hospital to create a system specific to its own population, which is regularly revalidated.

This study done in Bangalore Medical College and Research Institute, Bangalore, included 50 patients who presented to the Surgery Department and were diagnosed with hollow viscous perforation. All the patients were appropriately assessed and managed according to standard guidelines. Few of the other studies confirmed age as a decisive factor related with mortality; however, this study does not show any statistical significance. In other studies, patients with generalized peritonitis range from $30-66 \%$; in our study generalized peritonitis was present in about $66 \%$ of the patients. ${ }^{3.13}$ The influence of gender on prognosis has been shown of little importance in this study. Gender composition cited in other publications showed percentages varying from 43 to $52 \%$ females and 48 to $57 \%$ male. 14,$15 ; 80 \%$ were male in this study. Mean MPI score reported in literature for localized peritonitis is 19 (range 0 to 35 ) and in generalized peritonitis 26 to 27 points (range 11 to 43 ). ${ }^{16}$, which is similar to the values noted in this study. Duration of pain $>24$ hours, organ failure on admission and feculent exudate were found to be independently significant factors in predicting the morbidity among the study population. However, presence of diffuse peritonitis was not a significant factor in contrast to various other studies. ${ }^{17}$

\section{CONCLUSION}

There have been several attempts at creating a scoring system to predict mortality and morbidity risk after emergency surgery. Some scoring systems provide a prediction that approximates to the observed mortality rate for a cohort, but none is sufficiently accurate to rely upon when considering an individual patient. This is a validation study of the Mannheim Peritonitis Index scoring system for predicting the morbidity and mortality in patients with peritonitis due to hollow viscous perforation.

The results of this study proves that MPI scoring system is a simple and effective tool for assessing this group of patients and can be used as a guiding tool to decide on the management of the patient after the definitive procedure is done. Among the various variables of the scoring system, duration of pain, organ failure on presentation and presence of feculent exudates had a significant hand in predicting the eventual outcome of the patient.

\section{REFERENCES}

1. Wacha $H$, Linder $M M$, Feldman $U$, et al. Mannheim peritonitis index prediction of risk of death from peritonitis: construction of a static and validation of empirically based index. Theoretical surgery 1987;1:16977.

2. Billing A, Frohlich D, Schildberg FW. Prediction of outcome using the Mannheim peritonitis index in 2003 patients peritonitis study group. British journal of surgery 1994;81(2):209-13.

3. Pacelli F, Doglietto GB, Alfieri S, et al. Prognosis in intraabdominal infections, multivariate analysis on 604 patients. Arch Surgery 1996;131(6):641-5.

4. Notash AY, Salimi J, Rahimian H, et al. Evaluation of Mannheim peritonitis index and multiple organ failure score in patients with peritonitis. Indian journal of gastroenterology 2005;24:197-200.

5. Fry De, Pearlstein L, Fulton, et al. Multi system organ failure. Archives of Surgery 1985;202:685-93.

6. Varut Lohisiriwat, Siliruck Prapassivorakul, Darut Lohisiriwat, et al. Perforated peptic ulcer: clinical presentation, surgical outcomes and the accuracy of boeys scoring system in predicting post-operative morbidity and mortality. World journal of surgery 2009;33:80-5.

7. Kushumoto Yoshokon, Masayuki Nakagawa, Akihiko Watanabe, et al. Study of Mannheim peritonitis index to predict the outcome of patients with peritonitis. Japanese journal of gastroenterology surgery 2004;37(1):7-13.

8. Abrar Maqbool Quereshi, Afsheen Zafer, Saeed K, et al. Predictive power of Mannheim peritonitis index. J coll Physician's surgery Pakistan 2005;15(11):693-6.

9. Ohmann C, Wittmann DH, Wacha H. Prospective evaluation of prognostic scoring system in peritonitis. Eur J surg 1993;159(5):267-74.

10. Charles V Mann, Russel RCG, Williams NS. Bailey \& love's short practice of surgery. Chapman \& Hall 1995;22nd edn.

11. Charles Brunicardi F. Schwartz's principles of surgery. The McGraw-Hill Companies, Inc. 2010;9th edn:p 1766.

12. Wickel DJ, Cheadle WG, Mercer-Jones MA, et al. Poor outcome from peritonitis is caused by disease acuity and organ failure, not recurrent peritoneal infection. Ann Surg 1997;225(6):744-56. 
13. Navez B, Tassetti V, Scohy JJ, et al. Laparoscopic management of acute peritonitis. Br J Surg 1998;85(1):326.

14. Clagett M. Greek science in antiquity. New York: Barnes \& Noble, 1994;p 40.

15. Bassett JW. Exploration of the Abdomen. Springfield IL: Charles Thomas, 1967.
16. Seiler CA, Brugger L, Forssmann U, et al. Conservative surgical treatment of diffuse peritonitis. Surgery 2000;127(2):178-84.

17. Rodolfo L Bracho-Riquelme, Armando Melero-Vela, Aidee Torres-Ramíre. Mannheim peritonitis index validation study at the hospital general de durango (Mexico). Cir Ciruj 2002;70:217-25. 